\title{
Editorial
}

\section{CIOs Focus on Innovative ICT and Natural Disasters}

The International Academy of Chief Information Officers (IAC) annual meeting held in Manila during October, focused on the role of CIOs, ICT and Natural Disasters. Representatives from IAC chapters in 12 countries participated in a rich discussion of how CIOs can be prepared and assist in disaster risk reduction. The March 2011 tsunami and related disasters in Japan, recent flooding in Thailand, and emergency preparedness measures taken by the Philippine, China and other Asian governments, were the primary focus of the event. One session examined Human Capacity Building and how ICT can be integrated into preparedness plans of governments and businesses. Another examined e-Governance and Natural Disasters, assessing how disaster risk reduction and management can be integrated into e-Governance planning.

This issue presents an extensive report describing the Role of ICT in Public Safety and Emergency Management in China. It traces initiatives of the Chinese Gov- ernment in public safety emergency management from the SARS epidemic 2003 through an extensive emergency management program supervised by the State Council. As early as 2004 the State Council had issue four major categories of 25 special emergency plans and 80 State Council and departmental and provincial contingency plans. Identified are key measures that China has put in place for meteorological monitoring and early warning mechanisms. This factual analysis of the major steps China has taken to minimize impacts of natural disasters on its people and vast terrain an extremely valuable initiative. The outline of contingency plans that can be implemented before disasters occur, stresses these can be particularly important to all countries.

Russell Pipe, Editor in Chief 